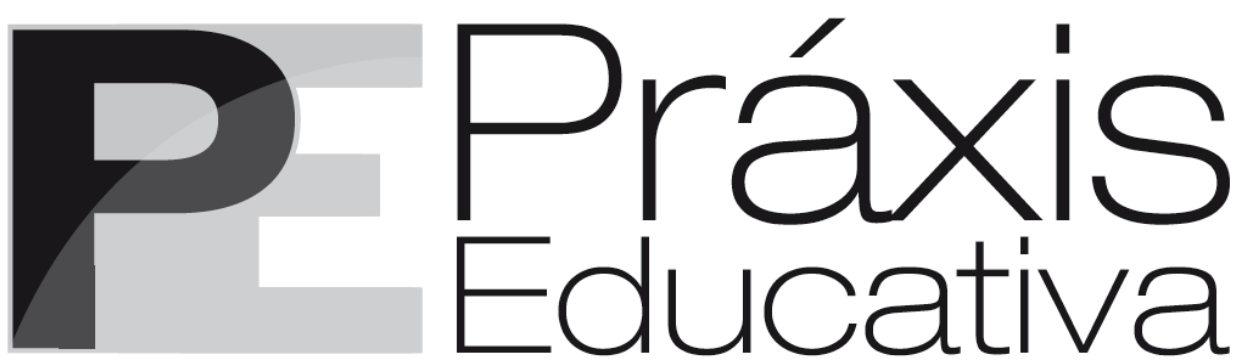

ISSN 1809-4031

eISSN 1809-4309

https://doi.org/10.5212/PraxEduc.v.15.17127.105

Apresentação

\title{
Seção temática: Adiando o fim da escola: perspectivas internacionais sobre Educação em tempos de pandemia
}

Geovana Mendonça Lunardi Mendes*

(iD) https://orcid.org/0000-0002-8848-7436

Marcia Denise Pletsch ${ }^{* *}$

iD https://orcid.org/0000-0001-5906-0487

Kamila Lockmann ${ }^{* * *}$

(D) https://orcid.org/0000-0002-1993-8088

Embaladas nas reflexões de Krenak (2019), de seu livro Ideias para adiar o fim do mundo, a seção Temática Adiando o fim da escola: a educação em tempos de pandemia traz para o debate as reconfigurações que estamos vivendo na educação em tempos de pandemia e, ao mesmo tempo, anuncia a potência da escola, como espaço formativo que não pode ser substituído ou reproduzido em outros espaços e por outros atores.

Com a crise sanitária, política, econômica e educacional instalada pela proliferação do Coronavírus (Covid-19) em diferentes partes do mundo, escolas, professores e famílias têm se reinventado para atender às demandas desse novo tempo. Com o intuito de dar continuidade aos processos de escolarização, muitas instituições escolares têm utilizado das tecnologias de educação a distância, de educação online, de educação remota, e outras diversas denominações, com foco na realização de atividades domiciliares.

\footnotetext{
* Professora do Programa de Pós-Graduação em Educação da Universidade do Estado de Santa Catarina (UDESC), Pesquisadora do Conselho Nacional de Desenvolvimento Científico e Tecnológico (CNPq). E-mail: $<$ geolunardi@gmail.com>.

** Professora do Programa de Pós-Graduação em Educação, Contextos Contemporâneos e Demandas Populares e do Programa em Humanidades Digitais da Universidade Federal Rural do Rio de Janeiro (UFRRJ), Pesquisadora do CNPq e Jovem Cientista da Fundação de Amparo à Pesquisa do Estado do Rio de Janeiro (Faperj). E-mail: $<$ marciadenisepletsch@gmail.com>.

*** Professora do Programa de Pós-Graduação em Educação da Universidade Federal do Rio Grande (FURG), Pesquisadora do CNPq. E-mail: <kamila.furg@gmail.com>.
} 
Seção temática: Adiando o fim da escola: perspectivas internacionais sobre Educação em tempos de...

Esta Seção temática foi organizado a partir de um conjunto de perguntas que mobilizam nosso pensamento e as discussões aqui materializadas: Será possível substituir o espaço da escola pelo espaço doméstico? Que reconfigurações e reduções temos observado nas práticas pedagógicas? Como fica o papel do professor nesse contexto? Como os currículos têm sido forjados considerando essa realidade? Que estratégias tecnológicas têm sido empregadas? Como grupos minoritários, como pessoas com deficiências e outros que residem em contextos sociais vulneráveis, têm participado desse processo? Que efeitos de in/exclusão temos percebido nessas práticas? Considerando que a atual crise é global, a presente Seção temática reúne textos de autores brasileiros e estrangeiros, localizados em países de diferentes continentes, com o objetivo de pensar acerca do lugar da escola e da educação nesse contexto.

Para discutir sobre tais aspectos, esta seção temática especial publicou 22 artigos e um documento no período de maio a novembro de 2020. Os textos trazem contribuições sobre diferentes temas e perspectivas envolvendo a Educação, assim como as possibilidades encontradas pelos diferentes países no período da pandemia da Covid-19 para diminuir o impacto do fechamento das escolas e das universidades. No total, são 13 artigos que analisam experiências nacionais e mais nove artigos de quatro regiões do mundo (América do Norte, América do Sul, África e Europa), os quais abrangem os seguintes países: Estados Unidos, Espanha, Portugal, Canadá, Colômbia, Itália, África do Sul e México. Além disso, temos a publicação de um documento.

O documento que compõe essa Sessão Especial, redigido por Simone de Fátima Flach e Daiana Camargo, da Universidade Estadual de Ponta Grossa, Paraná, trata-se de uma declaração de votos das Conselheiras representantes da Universidade Estadual da Ponta Grossa, sobre a Deliberação no 003/2020, do Conselho Municipal de Educação de Ponta Grossa, que institui o regime especial para o desenvolvimento das atividades escolares no âmbito do Sistema Municipal de Ensino de Ponta Grossa, no contexto da pandemia causada pelo novo Coronavírus - Covid19.

No conjunto de artigos, temos, do contexto internacional, o texto de Marta Estelles, da Universidade de Cantabria, Espanha, em parceria com Gustavo Fischman, da Universidade do Arizona, Estados Unidos. O artigo discute a urgência do conceito de Educação para uma Cidadania Global (ECG) pós-Covid-19. O texto critica a forma pela qual os organismos internacionais em um contexto de neoliberalização das políticas educacionais se apropriaram e estruturam uma espécie de versão "redentora" da ECG e defendem uma Educação para uma Cidadania Global mais realista pós-Covid-19, considerando a importância dos Estados no fortalecimento de iniciativas públicas para salvar vidas e atender às emergências das populações.

Jesús Rodríguez, Silvia López Gómez, Diana Marín Suelves e María Montserrat Castro Rodríguez, de diferentes Universidades da Espanha, analisam as propostas de materiais didáticos usados para crianças e jovens sobre Covid-19 na Espanha e refletem sobre a importância desse material. Ao longo do artigo, os autores apresentam a necessidade de que os futuros livros didáticos e outros materiais educativos devem incluir temas referentes, entre eles a prevenção da Covid-19.

O artigo de José Carlos Morgado, Joana Souza e José Augusto Pacheco, da Universidade do Minho, Portugal, apresenta uma discussão importante no campo dos estudos curriculares. Os pesquisadores abordam e problematizam conceitos como o isolamento curricular, digitalização curricular e o zoonismo vivenciados no período de isolamento social, mas ressaltam que, apesar das contradições e das adversidades, a escola irá resistir.

A experiência da Colômbia foi apresentada por David Rubio-Gaviria, da Universidade Pedagógica Nacional. O artigo problematiza o discurso sobre a "crise na educação" agravada pelas

Práxis Educativa, Ponta Grossa, v. 15, e2017127, p. 1-6, 2020

Disponível em: < https://www.revistas2.uepg.br/index.php/praxiseducativa> 
medidas de isolamento obrigatório devido à emergência sanitária mundial da Covid-19, que envolveu o fechamento de escolas em todo o mundo.

Os impactos da pandemia da Covid-19, no sistema educativo de Quebec/Canadá, são abordados por Kelly Russo, Marie-Odile Magnan e Roberta Soares a partir da análise de um conjunto de matérias jornalísticas e artigos de opinião publicados no período de 26 de março a 20 de maio de 2020, nos principais jornais da província de Quebec. O texto ilustra os diferentes impactos e rearranjos na educação escolar de crianças, entre quatro e 11 anos de idade, assim como discute como as desigualdades educacionais, já existentes, foram ampliadas com as ações de contenção do vírus.

Os desafios que a Covid-19 trouxe para a Educação italiana são abordados por Maria Ranieri, Cristina Gaggioli e Martha Kaschny Borges. As autoras analisam a didática da Educação a distância (DaD) e evidenciam o seu sucesso ou o seu fracasso. Para tal, por meio de um questionário online, as autoras analisam respostas de professores dos anos iniciais do Ensino Fundamental aos múltiplos desafios levantados pela $\mathrm{DaD}$ na fase de pandemia na Itália.

A resiliência e suas diferentes formas de manifestação durante o isolamento social na África do Sul são apresentadas por Liesel Ebersohn. O texto discute como a Covid-19 exige ações coletivas e colaborativas que podem ser fomentadas localmente. A autora evidencia que, na África, historicamente, se enfrentam adversidades extremas. Nesse caso, Ebersohn defende que a resiliência pode fornecer caminhos possíveis para responder à crise global da Covid-19.

Do México, recebemos o artigo de Inés Dussel, que discute como a pandemia criou o que se pode chamar de uma "domiciliação" do escolar. A invasão do "escolar" para o espaço doméstico, em particular quando se interrelaciona com as desigualdades pré-existentes e com as tecnologias e as pedagogias disponíveis, criam inúmeras problemáticas. Entre outros aspectos, um dos argumentos da autora é de que, contrariamente ao que afirmam os argumentos tecnofílicos, essas mudanças introduzem numerosas tensões difíceis de resolver e permitem ver a relevância da estrutura material e simbólica da escola para produzir um espaço outro que dê lugar a uma autonomia intelectual e afetiva progressiva.

O emprego da Educação a Distância é abordado no texto de Hugo Miguel Ramos dos Santos. O autor questiona a rápida emigração e imprevista das atividades educacionais para ambientes virtuais, revelando um conjunto de desafios de adaptação que questionam a preparação das escolas para adesão dessa modalidade de ensino. Para tal, o autor apresenta dados de um estudo realizado com docentes portugueses sobre as suas experiências de ensino online. Dentre os desafios apresentados nas entrevistas, destacaram-se: os desafios comunicacionais (monólogos digitais e exaustão psicológica), os pedagógicos (falta de competências, avaliação e sobrecarga de trabalhos e a impossibilidade de aulas práticas), os sociais (incompatibilidades com a vida pessoal e gestão de conflitos) e os tecnológicos (falta de recursos e tecnofobia).

No conjunto de textos que analisam o contexto brasileiro, temos o texto de Walter Omar Kohan, da Universidade do Estado do Rio de Janeiro. O autor inspirou-se e registrou a experiência de uma live apresentada com Maura Corcini Lopes (Universidade do Vale do Rio dos Sinos UNISINOS), organizada pela Associação Nacional de Pós-Graduação e Pesquisa em Educação (ANPEd). O texto aborda a forma em que o governo bolsonarista desenvolve uma necropolítica, a partir da trágica pandemia da Covid-19, e discute duas dimensões da escola: como instituição e como forma. Além disso, partindo da especificidade de três tempos presentes na educação: khrónos, kairós e aión, o autor retoma uma inspiração infantil para pensar o valor e o sentido da infância na educação. 
Seção temática: Adiando o fim da escola: perspectivas internacionais sobre Educação em tempos de...

No artigo de Roberto Rafael Dias da Silva, o debate recai sobre a escolarização juvenil em tempos de pandemia no Brasil. Para tanto, em um exercício de descrição e análise das disposições formativas que tendem a orientar as políticas e as práticas educativas na atualidade, o autor discute os arranjos teóricos que delineiam as teorizações sobre a educação contemporânea, as quais acabam formando e informando a percepção sobre o trabalho escolar.

Elsa Midori Shimazaki, Renilson José Menegassi e de Dinéia Ghizzo Neto Fellini apresentam como o ensino remoto adotado no Estado do Paraná impactou os processos de ensino e de aprendizagem de estudantes surdos a partir de uma pesquisa com cinco professores, três alunos e uma pedagoga de escola de educação bilíngue. A partir da análise Histórico-Cultural e Dialogismo em linguagem, os dados revelaram, entre outros aspectos, as dificuldades no preparo das aulas remotas para esse público e a vulnerabilidade dos alunos em termos econômicos para terem acesso às atividades remotas, assim como as dificuldades de compreensão e interpretação dos enunciados pelos estudantes surdos.

Dando continuidade na análise sobre o impacto da pandemia da Covid-19 na educação, Luciana Haddad Ferreira e Andreza Barbosa apresentam como as instituições de ensino, públicas e privadas, vêm se reorganizando em suas práticas a partir de um conjunto de determinações e das conduções adotadas no Brasil no contexto de crise, bem como os pressupostos que sustentam tais direcionamentos.

O ensaio de Paola Zordan e Verônica Domingues Almeida debate a educação nos tempos da Covid-19 a partir da problematização do papel do Estado, do paradigma linguístico nos currículos e do conteudismo, diante da paragem e da suspensão de atividades presenciais. As autoras discutem se o combate à escolarização vinculada ao futuro e à produtividade conteudista relega a formação.

A organização dos educadores de escolas localizadas em regiões ribeirinhas do Pantanal Sul-mato-grossense - as Escolas das Águas - para a manutenção da escolarização, no período da pandemia gerada pela Covid-19, foi discutida por Washington Cesar Shoiti Nozu e Mônica de Carvalho Magalhães Kassar, a partir de uma pesquisa qualitativa. Os dados foram analisados considerando-se o contexto amplo das políticas sociais, o que possibilitou a percepção de que populações vulneráveis podem ser mais fragilizadas em situações de exceção. Igualmente, os autores evidenciaram a presença da educação, mediada pelas Escolas das Águas, como um dos únicos elos da população local com o poder público.

O artigo de Carla Carvalho, Pedro Gottardi e Helen Rose Leite Rodrigues de Souza, por meio de um ensaio, discutem a ação e a subjetividade dos corpos[pandêmicos] na arte educação em meio ao caos e ao distanciamento social. Igualmente, mostram o corpo como lugar sensível e subjetivo, em um tempo no qual a Covid-19 coloca em suspensão a escola.

As políticas e as ações direcionadas para a Educação Infantil durante a pandemia da Covid19 são abordadas no artigo de Angela Scalabrin Coutinho e Valdete Côco. As autoras, a partir da análise de diferentes documentos, apresentam uma importante reflexão sobre as possibilidades e as especificidades da educação com as crianças pequenas. Igualmente, problematizam a adoção do ensino remoto para esse nível da educação, a importância da mobilização em defesa da educação pública e democrática, assim como ilustram a necessidade de vínculo entre a escola, a família e as crianças durante o isolamento social.

A possibilidade de uma "linguagem da educação" nas modalidades de Educação a Distância, é abordada por Bruno Antonio Picoli e Alexandre Anselmo Guilherme. A partir de pesquisa bibliográfica, especialmente das obras de Levinas e Gur-Ze'ev, os autores questionam

Práxis Educativa, Ponta Grossa, v. 15, e2017127, p. 1-6, 2020

Disponível em: < https://www.revistas2.uepg.br/index.php/praxiseducativa> 
se, nas modalidades de Educação a Distância, é possível criar as condições para uma resposta responsável ao chamado do Outro. Os pesquisadores concluem que a Educação a Distância não oferece condições para tal encontro, criando barreiras que impedem esse encontro do Eu ético com Outro.

Os desafios da pandemia do coronavírus e os desafios colocados para as esferas da vida humana e para as políticas sociais é o tema do artigo de Flavia Faissal de Souza e Débora Dainez. Por meio de uma pesquisa qualitativa exploratória com ancoragem na perspectiva históricocultural, as autoras analisam as condições de realização do ensino remoto emergencial direcionadas a um aluno com Transtorno do Espectro do Autismo, matriculado no $4^{\circ}$ ano do Ensino Fundamental. A partir dos resultados, as autoras apontam para a importância da escola na vida do aluno e apontam para o papel dessa instituição social como espaço coletivo de resistência políticopedagógica e mediadora dos processos de humanização.

As adaptação das atividades presenciais para atividades remotas no Estado do Rio Grande do Sul durante o distanciamento social causado pela Covid-19 são apresentadas no artigo de Karla Saraiva, Clarice Traversini e Kamila Lockmann, a partir da análise do material empírico de três sites de sindicatos gaúchos (Sindicato do Ensino Privado do Rio Grande do Sul - SINEPE/RS, Sindicato dos Professores do Estado do Rio Grande do Sul - SINPRO/RS e Centro dos Professores do Estado do Rio Grande do Sul - CPERS/RS), assim como de notícias publicadas na versão online do jornal Zero Hora no período entre o dia 16 de março e 31 de maio de 2020 . A análise do discurso de orientação foucaultiana evidenciou que o ensino remoto pode levar ao reforço dos mecanismos disciplinares, ao aprofundamento das desigualdades e produz uma docência levada à exaustão.

O texto de Fábio Merladet, Graça Reis e Maria Luiza Süssekind discute as noções de mundo e de fim de mundo, com apoio dos contos de Deszö Kosztolányi e Julio Cortázar e das perspectivas de expansão e invenção do presente no diálogo com as teorias de Michel de Certeau, Boaventura de Sousa Santos e Ailton Krenak. A partir deles, os autores fazem uma crítica ao capitalismo e que há resistência e criação na arte a partir de situações trazidas dos cotidianos na escola e na Universidade Popular do Movimentos Sociais (UPMS).

Por fim, Márcia Denise Pletsch e Geovana Mendonça Lunardi Mendes discutem as práticas educacionais propostas para crianças com a Síndrome Congênita do Zika Vírus (SCZV), durante o período de isolamento social causado pela pandemia do Coronavírus. A pesquisa de caráter qualitativa, analisa documentos sobre o ensino remoto produzidos em uma Rede Municipal de Educação da Baixada Fluminense, Rio de Janeiro, bem como dados de entrevistas semiestruturadas com cinco profissionais da Educação, que participaram de um Programa Piloto de Formação Continuada para atuar com crianças com a SCZV. Os resultados, entre outros aspectos, evidenciaram o empenho docente para desenvolver ações online que promovessem a interação e a participação das crianças nas atividades propostas, em parceria com as mães. As autoras também mostraram como a pandemia afetou a relação da escola com a família e a persistência/resiliência das professoras frente aos inúmeros desafios enfrentados durante o isolamento em sua atuação no magistério.

Assim, esta Seção temática compõe um quadro complexo dos movimentos educacionais produzidos como resposta aos impactos da pandemia da Covid-19 no Brasil e no mundo. Traz, para o debate, temas polêmicos que buscam analisar os efeitos produzidos na e para a educação por esses tempos incertos. Ademais, evidencia o aprofundamento das desigualdades sociais, as limitações do modelo de educação remota, o acirramento das exclusões de terminados grupos sociais, a intensificação do trabalho docente e os impedimentos de convívio com o outro que esses tempos acionam. De outra parte, revela a potência da escola, os esforços docentes, o envolvimento

Práxis Educativa, Ponta Grossa, v. 15, e2017127, p. 1-6, 2020 Disponível em: < https://www.revistas2.uepg.br/index.php/praxiseducativa> 
Seção temática: Adiando o fim da escola: perspectivas internacionais sobre Educação em tempos de...

da família e a resiliência do humano diante de um mundo em estado de exceção. É também por isso que conseguimos, mesmo nesses tempos sombrios, adiar o fim da escola e mostrar sua força como espaço público, comum e democrático de encontro com o outro.

\section{Referência}

KRENAK, A. Ideias para adiar o fim do mundo. São Paulo: Companhia das Letras, 2019. 